\title{
Месторождения стратегических и редкоземельных металлов как предмет биоиндикации, элементологии и металломики
}

\author{
Градов О.В.
}

\author{
ИНЭПХФ РАН, o.v.gradov@gmail.com, gradov@chph.ras.ru
}

\begin{abstract}
Месторождения стратегических и, в частности, ряда редкоземельных металлов, сопоставимые при анализе топографо-геодезической или картографической «колокализации» с распределениями биоты или отдельной группы организмов, аккумулирующей их, можно рассматривать как объекты биоиндикации вне зависимости от того, прямым визуальным или опосредованным инструментальным (спектральным, массспектрометрическим, электрохимическим и т.д.) методом осуществляется обнаружение металла. Тогда, с точки зрения изучения ассимиляции металла «живым веществом» и анализа биогенной миграции атомов, некоторые специфические формы нахождения металла в живом веществе, формы комплексообразования при формировании металлорганических и бионеорганических структур клетки должны быть сопоставимы отдельным формам нахождения металла в косной среде. Так как в супрамолекулярной химии имеет место зависимость свойств продукта от условий получения и путей реакций, координация металлов в живом веществе на неспецифических стадиях будет различной в зависимости от форм усвоения его им. В таком случае, помимо аддитивных (ICP-AS и ICP-MS (Vogiatzis, Zachariadis, 2014; Mounicou et al., 2010), рентгеноспектральный, рентгеноабсорбционный (Ascone, Strange, 2009) и т.д.) методов, с целью изучения данных особенностей должны использоваться химические структурные методы. Этот вопрос усложняется также опосредованием первичных (сорбционных и капиллярных) стадий биогенной миграции атомов почвой, обладающей комбинаторной совокупностью гуминовых кислот и фульвокислот (Perminova et al., 2005), представляющих собой стохастические (следовательно - разные по продуктам) «интермедиаты» и «аддукты» указанных стадий. Таким образом, привлечение структурных методов, предназначенных для изучения soft matter - частично-упорядоченных сред (Tolan, 1999; Stribeck, 2007; Imae et al., 2011; Amer 2009) в раздел которых, по причинам единства взаимодействий и связующих сил (David et al., 2014; Skjeltorp, Belushkin, 2004), попадают как биологические / биополимерные системы, так и коллоиды почв (Чухров, 1955, 1965), т.е. частично неорганические системы, является необходимым для неаддитивного массового анализа процессов, лежащих в основе биоиндикации и, следовательно - достоверного учета фризико-химической и биоколлоидной «параметризации» месторождений по данным биоиндикационного скрининга.
\end{abstract}

Вследствие этого, задача валидации эффективной металлогении месторождений стратегических и, в частности, ряда редкоземельных металлов, с использованием принципов биоиндикации приобретает не только картируемый «атомный» (исследуемый с помощью методов типа ICP-MS), геолого-географический, но и молекулярно-системно-биологический дискурс. Создаются условия для перехода от элементологии и микроэлементологии (в том числе - медицинской, эндемической) к элементомике и металломике (Li et al., 2008), в результате чего биоиндикация приобретает новый эвристический массив аналитических данных, содержащий в себе данные, которые могут быть использованы для изучения региональной и структурнорегиональной металлогении, фризико-химических условий рудообразования и форм нахождения, закономерностей распределения ряда стратегических металлов. Молекулярная систематика косного, металлорганического и бионеорганического вещества почвы и геосферы вообще в зонах металлогении является перспективным трендом изучения, на данный момент не являющимся мейнстримом, однако способным стать таковым при распространении новейших GIS-сопряженных методик многофакторного анализа. В связи с этим следует отметить принципиальные различия молекулярных форм усвоения металла представителями различных царств и специфику форм и механизмов усвоения в зависимости от таксонов: по этому принципу в анализе первичных ассимилянтов различают, например, металломику хемоавтотрофных микроорганизмов (Basu, 2008; Barton et al., 2007) и металломику растений (Salt, 2013). B то же время, неспецифической фиксацией металлов и, в итоге, собственной вирусной металломикой характеризуют и бактериофагов (Zhang et al., 2011), что рационально, исходя из известной связи между эпигенетикой и металломикой (Wrobel et al., 2009) и наличия содержащих их бактерий в автотрофных сообществах при некоторых формах рудообразования. Характеристической чертой множества подходов металломики является их применимость к палеобиогенному веществу (Edwards et al., 2014), что позволяет говорить об аккумуляционной достоверности данных металломики в аспекте построения палеогеологических карт при учете информации об отсутствии метаморфизирующей активности современных организмов на некотором уровне или регионе интереса (ROI). Существование работ в области металломики таких стратегических в современных условиях элементов как рутений, галлий, платина (Aleksenko et al., 2013; Esteban-Fernández et al., 2010; Ossipov et al., 2013) говорит о «стратегической» роли и потенциальном государственном значении российских прикладных исследований в области металломики с привязкой к GIS-координатам. Анализ переходов форм / состояний нахождения целевого металла в живом веществе должен учитывать специфику «белкового матрикса», иммобилизующего металл, то есть должен развиться анализ металлопротеома как формы структурной и надмолекулярной организации распределения данного металла (или совокупности сопряженных по металлогении элементов) в клетке (т.н. металлопротеомика) (Shi, Chance, 2013), эвристически-ценный при аппаратно-опосредованной комплексной «спектральной + структурно-химической» биоиндикации. 
Кроме позитивной прогностической роли подобные исследования на национальном уровне смогли бы уменьшить статистику металломных / элементомных патологий, возникающих как патологии клетки при регулярном контакте с металлом и соответствующих воздействиях на металлопротеом организма (Thierse et al., 2008), в частности, у рабочего персонала месторождений ряда стратегических металлов. Компартментализация отклика, различная для разных металлов, также является критерием аккумуляции с топографической привязкой и может быть использована не только для GIS-картирования областей риска, но и для металлорганической прогностики региональной металлогении по специфическим патологиям как органографрический биоиндикаторный метод, рассматривающий морфологию распределений элементома в организме. Существование васкулярной, миологической и нейрональной областей аккумуляции по ряду экзотических и утилитарно-значимых металлов (Easter et al., 2010; Moraes et al., 2012; Colvin et al., 2015), в частности, может быть применено как иллюстрация полезности данного подхода. Для большинства ныне значимых стратегических металлов, в отличие от широко изученных и используемых металлов, данных по компартментализации физиолого-биохимического отклика на элементомное / металломное воздействие и, следовательно, для построения «калибровочных» прогностических кривых биодиагностики не имеется. В связи с этим проведение широкомасштабных исследований в комплексно заданном и рассмотренном в настоящем тезисе ключе кажется оправданным, а в ряде случаев - критически необходимым.

\section{Литература:}

Aleksenko S.S., Matczuk M., LuX. et al. Metallomics for drug development: an integrated CE-ICP-MS and ICPMS approach reveals the speciation changes for an investigational ruthenium(III) drug bound to holotransferrin in simulated cancer cytosol // Metallomics, 2013, 5(8), 955-963.

Amer M.S. (Ed.) Raman Spectroscopy for Soft Matter Applications. Hoboken, New Jersey: Wiley, 2009.

Ascone I., Strange R. Biological X-ray absorption spectroscopy and metalloproteomics // Journ. Synchrotr. Radiat., 2009, 16(3), 413-421.

Barton L.L., Goulhen F., Bruschi M. et al. The bacterial metallome: composition and stability with specific reference to the anaerobic bacterium Desulfovibrio desulfuricans // Biometals, 2007, 20(3-4), 291-302.

Basu P. Microbial metallomics // Metallomics, 2013, 5(4), 274-275.

Colvin R.A., Lai B., Holmes W.R., Lee D. Understanding metal homeostasis in primary cultured neurons. Studies using single neuron subcellular and quantitative metallomics // Metallomics, 2015, 7(7), 1111-1123.

David D. et al. (Eds.) Electrostatics of Soft and Disordered Matter. Boca Raton, Florida: Pan Stanford Pub. (Taylor \& Francis Group), 2014.

Easter R.N., Chan O., Lai B. et al. Vascular metallomics // Vasc. Med., 2010, 15(1), 61-69.

Edwards N.P., Manning P.L., Bergmann U. et al. Leaf metallome preserved over 50 million years // Metallomics, 2014, 6(4), 774-782.

Esteban-Fernández D., Moreno-Gordaliza E., Cañas B. et al. Analytical methodologies for metallomics studies of antitumor Pt-containing drugs // Metallomics, 2010, 2(1), 19-38.

Imae T. et al (Eds.). Neutrons in Soft Matter Hoboken, New Jersey: Wiley, 2011.

Li Y.-F., Chen C., Qu Y. et al. Metallomics, elementomics, and analytical techniques // Pure Appl. Chem., 2008, 80(12), 2577-2594.

Moraes P.M., Santos F.A., Padilha C.C. et al. A preliminary and qualitative metallomics study of mercury in the muscle of fish from Amazonas, Brazil // Biol. Tr. Elem. Res., 2012, 150(1-3), 195-199.

Mounicou S., Szpunar J., Lobinski R. Inductively-coupled plasma mass spectrometry in proteomics, metabolomics and metallomics studies // Eur. Journ. Mass Spectrom., 2010, 16(3), 243-253.

Ossipov K., Foteeva L.S., Seregina I.F. et al. Metallomics for drug development: serum protein binding and analysis of an anticancer tris(8-quinolinolato)gallium(III) drug using inductively coupled plasma mass spectrometry // Anal. Chim. Acta., 2013, 785, 22-26.

Perminova I., Kudryavtsev A., Konstantinov A. et al. Stochastic chemistry of humic substances // Abstracts of Papers of the American Chemical Society, 2005, 230, U1796-U1797.

Salt D.E. Plant metallomics .// Metallomics, 2013, 5(9), 1088-1089.

Shi W., Chance M.R. Metallomics and metalloproteomics // Cell Mol. Life Sci., 2008, 65(19), 3040-3048.

Skjeltorp A.T., Belushkin A.V. (Eds.) Forces, Growth and Form in Soft Condensed Matter: At the Interface between Physics and Biology. New York, Boston, Dordrecht, London: Kluwer Academic Publishers, 2004.

Stribeck N. X-Ray Scattering of Soft Matter. Berlin, Heidelberg, New York: Springer, 2007.

Thierse H.J., Helm S., Pankert P. Metalloproteomics in the molecular study of cell physiology and disease // Meth. Mol. Biol., 2008, 425, 139-147.

Tolan M. X-Ray Scattering from Soft-Matter Thin Films. Berlin, Heidelberg, New York: Springer, 1999.

Vogiatzis C.G., Zachariadis G.A. Tandem mass spectrometry in metallomics and the involving role of ICP-MS detection: a review // Anal. Chim. Acta., 2014, 819, 1-14.

Wrobel K., Wrobel K., Caruso J.A. Epigenetics: an important challenge for ICP-MS in metallomics studies // Anal. Bioanal. Chem., 2009, 393(2), 481-486.

Zhang Y., Thompson R., Caruso J. Probing the viral metallome: searching for metalloproteins in bacteriophage $\lambda$ the hunt begins // Metallomics, 2011, 3(5), 472-481.

Чухров Ф.В. Коллоиды в земной коре. М.: Изд-во Академии наук СССР, 1955.

Чухров (丘赫洛夫) 胶体矿物学原理 .. 科学出版社, 1965. 